\title{
Evaluation of Urban Road Plant Landscape in Mianyang Based on Analytic Hierarchy Process
}

\author{
Mingying Zeng, Yuqing Gong* \\ Southwest University of Science and Technology, Mianyang, China \\ Email: *gongyq824@163.com
}

How to cite this paper: Zeng, M. Y., \& Gong, Y. Q. (2021). Evaluation of Urban Road Plant Landscape in Mianyang Based on Analytic Hierarchy Process. Art and Design Review, 9, 198-209.

https://doi.org/10.4236/adr.2021.92016

Received: April 27, 2021

Accepted: May 23, 2021

Published: May 26, 2021

Copyright $\odot 2021$ by author(s) and Scientific Research Publishing Inc. This work is licensed under the Creative Commons Attribution International License (CC BY 4.0).

http://creativecommons.org/licenses/by/4.0/ (c) (i) Open Access

\begin{abstract}
The analytic hierarchy process decomposes the problem into different components according to the nature of the problem and the overall goal to be achieved, and combines the factors at different levels according to the interrelationship between the factors and the affiliation relationship, forming a multi-level analysis structure model, So as to finally make the problem boil down to the determination of the relatively important weight of the lowest level (plans, measures, etc. for decision-making) relative to the highest level (the overall goal) or the scheduling of the relative order of superiority and inferiority. In this paper, 13 urban roads in Mianyang were selected as the research object. The Analytic Hierarchy Process (AHP) was used to establish the evaluation index weight judgment matrix from 3 criterion levels and 9 index levels, and the landscape evaluation system was constructed to make a comprehensive evaluation on the plant landscape of 13 urban roads. Results show that the index level of plant health, color composition, native plant community, diversity of plant landscape level and the degree of coordination with the surrounding landscape five indicators have important influence to city road plant landscape. The final evaluation result is: 6 roads were rated as second-level roads, and 7 roads were rated as third-level roads. On this basis, summarized the main characteristics of the urban road plant landscape in Mianyang, and some suggestions were put forward to guide the construction of urban road plant landscape in Mianyang.
\end{abstract}

\section{Keywords}

Analytic Hierarchy Process, Urban Road, Plant Landscape Evaluation

\section{Introduction}

The urban road plant landscape is the display window of the urban plant land- 
scape, and it is also an important embodiment of the urban plant landscape (Zou, 2020). Since the "Plant Landscape of Urban Greening System and Urban Ecology" held by the Chinese Society of Landscape

Architecture in Wenzhou in May 1986, the establishment of "ecological gardens" has been advocated in China. As an important part of the urban green space system, urban road plant landscape construction has become one of the main construction tasks of the gardening departments in various regions each year. At present, Chinese urban road plant landscape design has several problems, such as lack of integrity and individuality. For example, the urban road plant landscape style is not uniform, the street appearance is similar (He, 2019), the ornamental effect of plant landscape is too emphasized, and the ecological function of plants is ignored. Pay attention to short-term results regardless of long-term plans, etc ( $\mathrm{Li}, 2016)$. The study of urban road plant landscape evaluation and reconstruction strategy has positive significance for the construction of urban plant landscape.

At the same time, the use of analytic hierarchy process for urban road plant landscape evaluation is relatively mature in China. For example, Yang Gao and Jingkai Hu have adopted analytic hierarchy process (AHP method) to build an objectively suitable and targeted urban road plant landscape evaluation system, from qualitative (subjective understanding) And quantitative (objective measurement), evaluated the road plant landscape in Huangpu District of Guangzhou Development Zone (Gao \& Hu, 2017); Hui Lin and Junhui Chen used the analytic hierarchy process to analyze ecological value, landscape value, subjective perception, economic applicability and functionality Starting from various aspects, completed the evaluation of the plant landscape of Xiamen Huandao Road, and combined the results of this evaluation, and put forward suggestions for improvement of the color improvement project of Xiamen's plant landscape (Lin \& Chen, 2019); Shifeng Ding and Zhijian Feng applied the analytic hierarchy process, combined with Guangzhou The survey of the plant landscape in the central green belt of Xingang East Road in Shanghai has proposed ways to improve and enhance the quality and comfort of the road landscape (Ding \& Feng, 2019). This article is based on a thorough study of the analytic hierarchy process, combined with relevant domestic research, and the evaluation results are true and effective.

\section{Overview and Survey Methods of the Study Area}

\subsection{Overview of Geography and Climate of the Study Area}

Mianyang is located in the northwestern part of the Sichuan province, in the middle and upper reaches of the Fujiang River, between $30^{\circ} 42^{\prime}-33^{\circ} 03^{\prime}$ north latitude and $103^{\circ} 45^{\prime}-105^{\circ} 43^{\prime}$ east longitude. It belongs to the humid monsoon climate zone of the northern subtropical mountainous area with extreme maximum temperature. It is $36.1^{\circ} \mathrm{C}-39.5^{\circ} \mathrm{C}$, the extreme minimum temperature is $-4.5^{\circ} \mathrm{C}--7.3^{\circ} \mathrm{C}$, and the average temperature is $14.7^{\circ} \mathrm{C}-17.3^{\circ} \mathrm{C}$. The precipita- 
tion is relatively abundant, and the inter-annual variation of precipitation is very large. The average annual precipitation is 825.8 - $1417 \mathrm{~mm}$. Its distribution characteristics are: less in the north and south, more in the middle; less in the east and more in the west, and generally the wind speed is low.

\subsection{Plot Setting and Survey Methods}

The data used in this article was collected from July to December 2019. Select Changhong Avenue, Yuejin Road, Youxian Road, west of Xishan Road, Mianzhou Avenue, Mianxing Road, Linyuan Road, Jiuzhou Avenue, Jiannan Road West, Feiyun Avenue, Dongjin Road, Chuangye Avenue and Chengnan Road in Mianyang. A total of 13 typical urban arterial roads are used as the research objects. The plant configuration of each road is investigated, and the plant species, ornamental characteristics, plant landscape level diversity, plant health status, seasonal landscape, color composition, etc. are recorded in detail (Ren, 2017). Simultaneous image collection to reflect the main features of the plant landscape of each urban road. Each road retains 1 - 3 photos that best reflect the characteristics of its plant landscape as the basis for evaluation.

\section{Construction of Analytic Hierarchy Process Evaluation Model}

\subsection{Concept}

The analytic hierarchy process, abbreviated as AHP, refers to a complex multi-objective decision-making problem as a system, the goal is decomposed into multiple goals or criteria, and then decomposed into multiple indicators (or criteria, constraints) several levels, through qualitative indicators fuzzy The quantitative method calculates the hierarchical single ranking (weight) and the total ranking as a systematic method for target (multi-index) and multi-scheme optimization decision-making. That is to say, the decision-making problem is decomposed into different hierarchical structures according to the order of the general goal, the sub-goals of each level, the evaluation criteria, and the specific plan for investment. The priority weight of a certain element of the level, and finally the weighted sum method recursively and the final weight of each alternative plan to the overall goal, the one with the largest final weight is the optimal plan (Xu, 1988).

\subsection{Determination of Evaluation Indicators}

Consult the research methods in the literature, combined with the characteristics of Mianyang, according to the establishment principles of indicators and the framework model of the evaluation system. After contacting 20 experts in landscape and related fields, after 3 rounds of expert opinion consultation, a hierarchical structure model of urban road plant landscape evaluation in Mianyang was established (Figure 1) (Qi, 2018). The model is divided into three layers: the first layer is the target layer (A); the second layer is the criterion layer (B), in- 
cluding three aspects: ecological function, aesthetic function, and service function; the third layer is the standard layer (C), which is subordinate to the criterion layers, including the richness of life types, the diversity of vegetation types, the health of plants, the vernacular characteristics of plant communities, the degree of coordination with surrounding landscapes, seasonal landscapes, color composition, anti-vertigo, and shading effects.

\subsubsection{Index Weight Calculation}

According to the established hierarchical structure model of urban road plant landscape evaluation in Mianyang, questionnaires were issued to experts in landscape and related fields to determine the weights of indicators. The questionnaire includes questionnaire 1 and 2, targeting 10 teachers and students with professional backgrounds related to landscape and greening, and 10 people with non-professional backgrounds. Questionnaire 1 Invited participants from the second level, compare and score multiple indicators belonging to the same indicator in the previous level, that is, compare the relative importance of the two indicators $b_{i}$ and $b_{j}$ each time, and use $b_{i j}$ to represent the relative importance For the comparison results, the 1 - 9 scale method (Table 1) was used for comparison. Professionals and non-professionals were scored and then converted into proportions. The conversion ratio was 2:1 (Yuan, 2013). Questionnaire 2

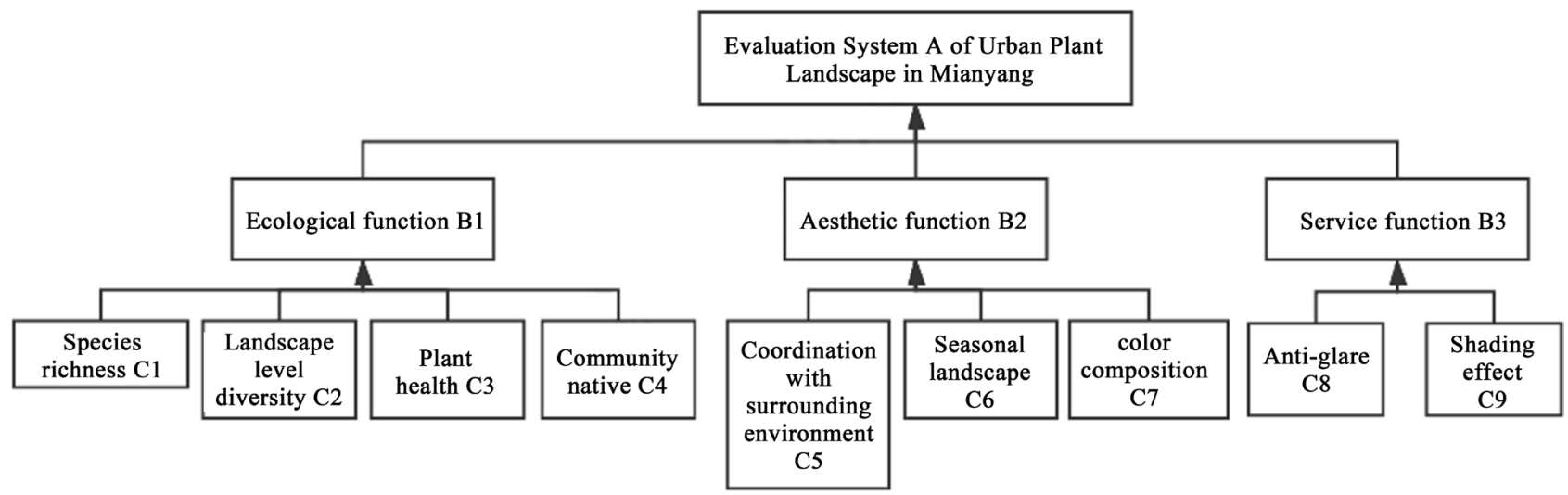

Figure 1. Hierarchical structure model of urban road plant landscape evaluation in Mianyang.

Table 1 . The scaling principles of the analytic hierarchy process

\begin{tabular}{ll}
\hline Scaling & Meaning \\
\hline 1 & Means to compare two factors with the same importance \\
3 & Means to compare two factors, one factor is slightly more important than the other \\
5 & Means to compare two factors, one factor is obviously more important than the other \\
7 & Means to compare two factors, one factor is more important than the other \\
9 & $\begin{array}{l}\text { Means to compare two factors, one factor is extremely important than the other } \\
2,4,6,8\end{array} \quad \begin{array}{l}\text { The median of the above two adjacent judgments } \\
\text { reciprocal Judgment } a_{i j} \text { of the comparison of factors i and } \mathrm{j}, \text { then the judgment } \\
\text { of factors } j \text { and } i a_{j i}=1 / a_{i j}\end{array}$ \\
\hline
\end{tabular}


invited participants to score the indicators of each road, with a minimum of 0 points and a maximum of 10 points.

\subsubsection{Constructing a Judgment Matrix}

The judgment matrix is constructed based on the data result of questionnaire 1 , and all the comparison results are represented by $A-B i=\left(b_{i j}\right) n \times n$ ( $n$ is the order of the judgment matrix). Calculate the maximum eigenvalue $\lambda_{\max }$ of the judgment matrix $A-B i$ and the corresponding eigenvector $\mathrm{W}$, and then normalize the eigenvector $W$, that is, the vector of the relative importance (weight) of the index of the same level to the index of the previous level. This process is called hierarchical single sort. In the consistency test of the judgment matrix, when CR < 0.10 , the inconsistency of the judgment matrix is considered to be within the allowable range, and the consistency test is passed ( $\mathrm{Ba}, 2013)$.

\subsubsection{Calculate the Comprehensive Evaluation Score}

Based on full reference to other urban landscape evaluation documents and soliciting expert opinions, the scoring standards for 9 indicators were formulated (Table 2). Using a 10-point system, the highest score is 10 points, indicating the best performance of the indicator, and the lowest score is 0 points, indicating the worst performance. Some indicators are divided into 3 levels of excellent, medium, and extremely poor, with the highest coefficients of each level being 10, 6 , and 2 respectively; some indicators are divided into 5 levels, namely excellent, good, medium, poor, and extremely poor. The highest coefficients are 10, 8, 6, 4, 2 (Shen, Li, \& Wang, 2018). Experts score the various indicators of each road according to the index scoring standard, and average the scoring results to obtain the scoring value of each indicator, and then calculate the comprehensive evaluation score of each road through the following formula:

$$
V=\sum_{i=1}^{n} W_{i} F_{i}
$$

where: $V$ is the comprehensive quality score of a plant landscape unit; $F_{i}$ is the score of a certain evaluation factor; $W_{i}$ represents the weight of the factor; $F_{i} W_{i}$ is the evaluation score of the factor (Liao, 2019). According to the total ranking weight value of the index layer in Table 2, the comprehensive evaluation score of the plant landscape unit is calculated. In order to make the dimension of the evaluation factor consistent, each value of the quantitative factor is multiplied by 10 , and finally the comprehensive quality score of a plant landscape unit is obtained.

$$
C_{C E I}=S / S_{0} \times 100 \%
$$

where: $C_{C E I}$ is the comprehensive evaluation index of a certain plant landscape unit; $S$ is the comprehensive evaluation score of the landscape unit; $S_{0}$ is the ideal value of the comprehensive evaluation of the landscape unit. Based on the $C_{C E P}$ determine the evaluation grade of each unit, $80 \%-100 \%, 60 \%-80 \%, 40 \%-60 \%$, $0-40 \%$ are respectively grade I, II, III, and IV. 
Table 2. Evaluation indicators and scoring standards of urban road plant landscape units in Mianyang.

\begin{tabular}{|c|c|c|c|c|c|c|}
\hline \multirow{2}{*}{ Criterion layer } & \multirow{2}{*}{ standard floor } & \multicolumn{5}{|c|}{ Evaluation standard } \\
\hline & & $10-8$ & $7-6$ & $5-4$ & $3-2$ & $1-0$ \\
\hline \multirow{4}{*}{$\begin{array}{l}\text { Ecological } \\
\text { functionB1 }\end{array}$} & $\begin{array}{l}\text { Species richness }\left(\mathrm{N}_{1}\right) \\
\mathrm{C} 1\end{array}$ & $\mathrm{~N} \geq 10$ & $10>\mathrm{N} \geq 8$ & $8>N \geq 6$ & $6>N \geq 4$ & $\mathrm{~N}<4$ \\
\hline & $\begin{array}{l}\text { landscape level } \\
\text { diversity C2 }\end{array}$ & \multicolumn{2}{|c|}{$\begin{array}{c}\text { There are three levels of } \\
\text { collocation }\end{array}$} & \multicolumn{2}{|c|}{$\begin{array}{l}\text { Two hierarchical collocations such as } \\
\text { joe }+ \text { irrigation or joe + grass }\end{array}$} & Single hierarchy \\
\hline & Plant health C3 & \multicolumn{2}{|c|}{$\begin{array}{l}\text { The canopy is full, the leaves are } \\
\text { bright, the plant grows } \\
\text { vigorously, and there is no pests } \\
\text { or diseases. }\end{array}$} & \multicolumn{2}{|c|}{$\begin{array}{l}\text { The crown is not full enough, the leaf } \\
\text { color is darker, there are certain } \\
\text { diseases and insect pests, and the plant } \\
\text { growth is stronger }\end{array}$} & $\begin{array}{l}\text { Plant growth is weak, with } \\
\text { obvious pests and diseases }\end{array}$ \\
\hline & $\begin{array}{l}\text { Indigenous Plant } \\
\text { Community }\left(\mathrm{N}_{2}\right) \mathrm{C} 4\end{array}$ & $\mathrm{~N}_{2}>90 \%$ & $90 \%>\mathrm{N}_{2}>80 \%$ & $80 \%>\mathrm{N}_{2}>70 \%$ & $70 \%>\mathrm{N}_{2}>60 \%$ & $\mathrm{~N}_{2}<60 \%$ \\
\hline \multirow{3}{*}{$\begin{array}{l}\text { Aesthetic } \\
\text { functionB2 }\end{array}$} & $\begin{array}{l}\text { Harmony with } \\
\text { surrounding } \\
\text { landscape C5 }\end{array}$ & \multicolumn{2}{|c|}{$\begin{array}{l}\text { Very coordinated with the } \\
\text { surrounding soft and hard } \\
\text { landscape }\end{array}$} & \multicolumn{2}{|c|}{$\begin{array}{l}\text { Generally coordinated with the } \\
\text { surrounding soft and hard landscape }\end{array}$} & $\begin{array}{l}\text { Inconsistent with the } \\
\text { surrounding soft and hard } \\
\text { landscape }\end{array}$ \\
\hline & Seasonal landscape C6 & \multicolumn{2}{|c|}{$\begin{array}{l}\text { The overall seasonal changes of } \\
\text { plants are obvious }\end{array}$} & \multicolumn{2}{|c|}{$\begin{array}{c}\text { There are parts of the plants exist phase } \\
\text { change season }\end{array}$} & Almost no seasonal change \\
\hline & $\begin{array}{l}\text { color composition } \\
\qquad\left(\mathrm{N}_{3}\right) \mathrm{C7}\end{array}$ & \multicolumn{2}{|c|}{ More than 4 distinct colors } & \multicolumn{2}{|c|}{ More than 3 distinct colors } & Less than 3 distinct colors \\
\hline \multirow[t]{2}{*}{$\begin{array}{c}\text { service } \\
\text { functionB3 }\end{array}$} & Anti-glare C8 & \multicolumn{2}{|c|}{$\begin{array}{l}\text { Strong anti-glare ability, which } \\
\text { can basically avoid the influence } \\
\text { of traffic lights on traffic and } \\
\text { pedestrians at night }\end{array}$} & \multicolumn{2}{|c|}{$\begin{array}{l}\text { The anti-glare ability is strong, which } \\
\text { can reduce the impact of traffic and } \\
\text { pedestrians on the traffic lights at night }\end{array}$} & $\begin{array}{l}\text { The anti-glare ability is } \\
\text { weak, and it cannot reduce } \\
\text { the impact of the traffic } \\
\text { lights on the traffic and } \\
\text { pedestrians at night }\end{array}$ \\
\hline & Shading effect C9 & $\begin{array}{l}\text { Shading effect } \\
\text { is very good }\end{array}$ & $\begin{array}{l}\text { Good shading } \\
\text { effect }\end{array}$ & $\begin{array}{l}\text { Better shading } \\
\text { effect }\end{array}$ & $\begin{array}{c}\text { Moderate shading } \\
\text { effect }\end{array}$ & No shading effect \\
\hline
\end{tabular}

Among them, species richness, plant landscape level diversity, plant community nativeness, and color composition are directly scored by experts as quantitative indicators, and the remaining 5 qualitative indicators are scored by experts according to the scoring standards in the form of slideshows of landscape unit photos. In order to make the evaluation results true and effective, the slides will be played twice. The first time will mainly introduce the names of the roads and plant characteristics, so that the experts will have a basic understanding of the roads participating in the evaluation; the second time will be played every time. An expert recorded the scores of the various indicators of each road on the evaluation form in the order of the slide show.

\section{Results and Analysis}

\subsection{Analysis of Evaluation Indicators}

The results show that all judgment matrices have passed the consistency test (Table 3), and the results are reasonable and effective. According to the judgment matrix, the weight value of the evaluation index factors for the improvement of plant landscape colorization is calculated and the total weight of the landscape evaluation index factors is finally determined (Table 4). 
It can be seen from Table 4 that the weight value of ecological function (0.6434) is the highest in the criterion level, indicating that the current urban green space plant landscape construction focuses on ecological construction; followed by aesthetic function (0.2828) and service function (0.0738), indicating that road greening attaches importance to it. In terms of beautification and environmental improvement, the service function is second; in terms of ecological function, plant health has the highest weight (0.3704), and plant species richness is the lowest (0.0523); in terms of aesthetic function, color composition (0.1881) has the highest weight. Followed by the degree of coordination with the

Table 3. Judgment matrix and consistency test.

\begin{tabular}{|c|c|c|c|c|c|c|c|c|c|c|}
\hline Hierarchical model & & & & & & $W_{I}$ & $\lambda$ & $\mathrm{CI}$ & RI & $\mathrm{CR}$ \\
\hline \multirow[t]{4}{*}{$A-B_{i}$} & $\mathrm{~A}$ & $\mathrm{~B}_{1}$ & $\mathrm{~B}_{2}$ & $\mathrm{~B}_{3}$ & & & 3.0649 & 0.0325 & 0.58 & $0.0559<0.1$ \\
\hline & $\mathrm{B}_{1}$ & 1 & 3 & 7 & & 0.6434 & & & & \\
\hline & $\mathrm{B}_{2}$ & $1 / 3$ & 1 & 5 & & 0.2828 & & & & \\
\hline & $\mathrm{B}_{3}$ & $1 / 7$ & $1 / 5$ & 1 & & 0.0738 & & & & \\
\hline \multirow[t]{5}{*}{$B_{1}-C_{i}$} & $\mathrm{~B}_{1}$ & $\mathrm{C}_{1}$ & $\mathrm{C}_{2}$ & $\mathrm{C}_{3}$ & $\mathrm{C}_{4}$ & & 4.1237 & 0.0412 & 0.9 & $0.0458<0.1$ \\
\hline & $\mathrm{C}_{1}$ & 1 & $1 / 2$ & $1 / 5$ & $1 / 3$ & 0.0813 & & & & \\
\hline & $\mathrm{C}_{2}$ & 2 & 1 & $1 / 7$ & $1 / 3$ & 0.1064 & & & & \\
\hline & $\mathrm{C}_{3}$ & 5 & 7 & 1 & 3 & 0.5757 & & & & \\
\hline & $\mathrm{C}_{4}$ & 3 & 3 & $1 / 3$ & 1 & 0.2367 & & & & \\
\hline \multirow[t]{4}{*}{$B_{2}-C_{I}$} & $\mathrm{~B}_{2}$ & $\mathrm{C}_{5}$ & $\mathrm{C}_{6}$ & $\mathrm{C}_{7}$ & & & 3.0858 & 0.0429 & 0.58 & $0.074<0.1$ \\
\hline & $\mathrm{C}_{5}$ & 1 & 3 & $1 / 4$ & & 0.2311 & & & & \\
\hline & $\mathrm{C}_{6}$ & $1 / 3$ & 1 & $1 / 5$ & & 0.1038 & & & & \\
\hline & $\mathrm{C}_{7}$ & 4 & 5 & 1 & & 0.6651 & & & & \\
\hline \multirow[t]{3}{*}{$B_{3}-C i$} & $\mathrm{~B}_{3}$ & $\mathrm{C}_{8}$ & $\mathrm{C}_{9}$ & & & & 2 & 0 & 0 & $0<0.1$ \\
\hline & $\mathrm{C}_{8}$ & 1 & $1 \backslash 7$ & & & 0.125 & & & & \\
\hline & $\mathrm{C}_{9}$ & 7 & 1 & & & 0.875 & & & & \\
\hline
\end{tabular}

Table 4. Comprehensive evaluation model of urban road plant landscape in Mianyang and the weight of each index.

\begin{tabular}{|c|c|c|c|c|c|}
\hline Target layer & Criterion layer & standard floor & Unit weight & Total weight & Sort by total weight \\
\hline \multirow{9}{*}{$\begin{array}{c}\text { Evaluation System of Urban } \\
\text { Road Plant Landscape } \\
\text { in Mianyang A }\end{array}$} & \multirow{4}{*}{$\begin{array}{l}\text { Ecological function } \\
\text { B1 }(0.6434)\end{array}$} & Species richnessC1 & 0.0813 & 0.0523 & 7 \\
\hline & & landscape level diversityC2 & 0.1064 & 0.0685 & 4 \\
\hline & & Plant healthC3 & 0.5757 & 0.3704 & 1 \\
\hline & & Indigenous Plant CommunityC4 & 0.2367 & 0.1523 & 3 \\
\hline & \multirow{3}{*}{$\begin{array}{l}\text { Aesthetic function } \\
\text { B2 }(0.2828)\end{array}$} & Harmony with surrounding landscapeC5 & 0.2311 & 0.0654 & 5 \\
\hline & & Seasonal landscapeC6 & 0.1038 & 0.0294 & 8 \\
\hline & & color compositionC7 & 0.6651 & 0.1881 & 2 \\
\hline & \multirow{2}{*}{$\begin{array}{l}\text { service function } \\
\text { B3 }(0.0738)\end{array}$} & Anti-glareC8 & 0.125 & 0.0092 & 9 \\
\hline & & Shading effectC9 & 0.875 & 0.0646 & 6 \\
\hline
\end{tabular}


surrounding landscape (0.0654) and seasonal landscape (0.0294); in terms of service functions, the anti-glare (0.0092) weight is inferior to the shading effect (0.0646). The total weight value of the index after the weights are unified shows that the health status of plants (0.3704), color composition (0.1881) and the vernacular characteristics of plant communities (0.1523) are the most important factors influencing the evaluation of urban road plant landscape.

\subsection{Comprehensive Evaluation Results}

According to the calculation formula, the comprehensive evaluation score of each unit is calculated separately (Table 5), and the evaluation level is determined according to the corresponding comprehensive evaluation index. It can be seen from Table 6 that the final evaluation result is 6 grade II roads, namely Chengnan Road, Dongjin Road, Jiuzhou Avenue, Linyuan Main Road, Mianzhou Avenue and Changhong Avenue, accounting for $46 \%$ of the total; 7 grade III roads, respectively Venture Avenue, Feiyun Avenue, West Section of Jiannan Road, Mianxing Road, West Section of Xishan Road, Youxian Road and Yuejin Road, accounting for $54 \%$ of the total, without Grade I and Grade IV. The main problems of the 13 roads are:

- The plant species is not rich enough, and the plant species of the 6 roads are less than 8. Among them, there are only 3 plants on Mianxing Road and Feiyun Avenue, and only 1 species on West Section of Xishan Road;

- Plant color the composition is relatively simple. Among the 13 roads, only Chengnan Road and Jiuzhou Avenue are rich in plant colors and are composed of 4 color systems, Yuejin Road, Mianxing Road and Feiyun Avenue have 2 types, and West Section of Xishan Road has only 1 type; 3 . The coordination between the road plant landscape and the surrounding landscape is

Table 5. Comprehensive evaluation scores of urban road plants in Mianyang.

\begin{tabular}{|c|c|c|c|c|c|c|c|c|c|c|}
\hline & $\mathrm{C} 1$ & $\mathrm{C} 2$ & $\mathrm{C} 3$ & $\mathrm{C} 4$ & C5 & C6 & $\mathrm{C7}$ & $\mathrm{C} 8$ & C9 & Total score \\
\hline Chengnan Road & 0.4708 & 0.6846 & 2.5410 & 0.4569 & 0.3732 & 0.1761 & 1.5047 & 0.0500 & 0.3508 & 6.6080 \\
\hline Venture Avenue & 0.3662 & 0.6846 & 2.4854 & 0.4569 & 0.4202 & 0.1802 & 0.9405 & 0.0565 & 0.3508 & 5.9412 \\
\hline Dongjin Road & 0.3662 & 0.6846 & 2.7003 & 0.6092 & 0.4764 & 0.2389 & 0.9405 & 0.0433 & 0.4063 & 6.4657 \\
\hline Feiyun Avenue & 0.1046 & 0.3423 & 2.3817 & 1.5229 & 0.4013 & 0.1802 & 0.3762 & 0.0447 & 0.4154 & 5.7693 \\
\hline Jiuzhou Avenue & 0.3662 & 0.6846 & 2.7003 & 0.6092 & 0.4947 & 0.2307 & 1.5047 & 0.0736 & 0.5078 & 7.1717 \\
\hline Linyuan Road & 0.5231 & 0.6846 & 2.1706 & 0.7615 & 0.4111 & 0.1594 & 0.9405 & 0.0328 & 0.4063 & 6.0898 \\
\hline Mianxing Road & 0.1046 & 0.3423 & 2.3817 & 1.5229 & 0.3732 & 0.1553 & 0.3762 & 0.0395 & 0.4709 & 5.7666 \\
\hline Mianzhou Avenue & 0.4708 & 0.6846 & 2.3298 & 0.7615 & 0.4294 & 0.1846 & 0.9405 & 0.0433 & 0.4612 & 6.3057 \\
\hline Youxian Road & 0.2615 & 0.6846 & 2.3298 & 0.6092 & 0.4385 & 0.1970 & 0.9405 & 0.0460 & 0.3689 & 5.8760 \\
\hline Yuejin Road & 0.1569 & 0.3423 & 2.5928 & 0.9138 & 0.4483 & 0.2307 & 0.5643 & 0.0644 & 0.5078 & 5.8213 \\
\hline Changhong Avenue & 0.3662 & 0.3423 & 2.4854 & 1.0660 & 0.4575 & 0.1383 & 1.1285 & 0.0381 & 0.4335 & 6.4558 \\
\hline
\end{tabular}


Table 6. Evaluation results of urban road plant landscape in Mianyang.

\begin{tabular}{cccc}
\hline Road & Comprehensive evaluation index/\% & Landscape level & Rank \\
\hline Kyushu Avenue & 71.72 & II & 1 \\
Chengnan Road & 66.08 & II & 2 \\
Dongjin Road & 64.66 & II & 3 \\
Changhong Avenue & 64.56 & II & 4 \\
Mianzhou Avenue & 63.06 & II & 5 \\
Linyuan Road & 60.90 & II & 6 \\
Venture Avenue & 59.41 & III & 7 \\
West of Xishan Road & 58.83 & III & 8 \\
Youxian Road & 58.76 & III & 9 \\
Yuejin Road & 58.21 & III & 10 \\
Feiyun Avenue & 57.69 & III & 11 \\
Mianxing Road & 57.67 & III & 12 \\
West Section of Jiannan Road & 50.30 & III & 13 \\
\hline
\end{tabular}

low. In the process of expert scoring, only Dongjin Road, Jiuzhou Avenue and Changhong Avenue achieved an average score of more than 7 points.

Among the second-class roads, Jiuzhou Avenue has the highest comprehensive evaluation index. There are nine kinds of plants on Jiuzhou Avenue, and there are three kinds of plants with arbor, shrub and grass. The color composition is 4 color systems. The seasonal landscape has an average score in the expert's evaluation. 7.86 points, the average score of anti-glare and shading effect is higher than 7.8 points. Among the third-class roads, the comprehensive evaluation index of the west section of Jiannan Road is the lowest. There are only 4 plant species in the west section of Jiannan Road, and only $50 \%$ of native plants. The coordination degree with the surrounding landscape and the average score of the seasonal landscape during the expert evaluation process are low, score is less than 6 points, because it is a newly built road and the plants are still in their juvenile stage, the average score for anti-glare and shading effects is also less than 5 points.

\subsection{Suggestions for the Transformation of Urban Road Plants in Mianyang}

Based on the above evaluation results, suggestions are made for the improvement of places with poor plant landscapes on urban roads in Mianyang:

- Rich plant color composition. The color composition of urban road plants in Mianyang is relatively monotonous, and the rich colors are more likely to leave a deep impression. City builder can plant purple, blue and other color plants to increase the color richness of the urban plant landscape.

- Increase plant species. There are a maximum of 12 species of plants on the main road in the garden, including camphor, osmanthus, heather, Schefflera, 
camellia, golden coral, safflower locust, palm bamboo, cycad, Ligustrum lucidum, Ophiopogon japonicus and Rudbeckia; and there is only one type of British Sycamore on the west section of Xishan Road. Although there are changes in leaf color of British Sycamore in autumn and winter, it is slightly monotonous, especially after falling leaves in winter, it will affect the plant landscape of the entire road.City builder can plant some ground cover plants such as rudbeckia, enriching plant species can also increase the level of plant landscape.

- When planting plants, appropriate consideration should be given to anti-glare. According to experts'scores on the anti-glare ability of 13 roads, it can be seen that the anti-glare ability of urban road plants in Mianyang is poor. The average score of 8 roads is less than 5 points, because some urban roads cannot be due to limited road width. The establishment of a green belt for the middle sub-vehicle leads to weak anti-glare ability. The middle sub-vehicle can be appropriately added under permitted conditions, which can not only enrich the urban road plant landscape, but also effectively ensure the safety of vehicles and pedestrians.

\section{Summary and Discussion}

\subsection{Main Features of Urban Road Plant Landscape in Mianyang}

Combining the actual survey situation and the comprehensive evaluation results of the landscape, the main features of the urban road plant landscape in Mianyang can be summarized as follows:

- In terms of ecological functions, the plant health status is good, and the plant community structure is stable, mostly with a three-layer composite structure of arbor, shrub and grass; some road plants are rich in species, but most road plants are relatively single, and the plant communities are generally native.

- In terms of aesthetic functions, it has a high degree of coordination with the surrounding landscape, but the overall urban road plant landscape lacks uniformity; the color composition is mainly green, red and yellow are the second, and the rest are not many, due to plant species The choice is mainly based on green plants, resulting in unobvious plant seasonal landscape, and some roads have the problem that plants block each other and affect their seasonal landscape.

- In terms of service functions, some roads do not have a green belt in the middle, which leads to weak anti-glare capabilities. However, the green belts and sidewalk plants on both sides have a certain anti-glare ability. Most urban roads have better shading effects and can provide a good understory space for vehicles and pedestrians.

\subsection{Discussion}

This paper uses the analytic hierarchy process to comprehensively evaluate and construct an evaluation model to evaluate the urban road plant landscape in 
Mianyang. Based on the opinions of landscape-related professional experts, the landscape evaluation system and evaluation index weight judgment matrix is established, and the final evaluation results are obtained: 6 roads were rated as second-level roads, and 7 roads were rated as third-level roads... After field research and reading literature, while providing support for the construction of urban road plant landscape in Mianyang, it also plays a guiding role in the comprehensive study of the quantification of Mianyang and urban road plant landscapes with similar geographic locations. Through this evaluation, it is found that there are problems in the color composition, plant species richness and anti-glare ability of the urban road plant landscape in Mianyang. The optimization method of the plant landscape is proposed in response to these problems, aiming to improve the urban road green space. All aspects of value enable it to better serve as a window for the city, and at the same time better meet the needs of urban green space development.

\section{Conflicts of Interest}

The authors declare no conflicts of interest regarding the publication of this paper.

\section{References}

Ba, C. B. (2013). Research on Noise Reduction and Influencing Factors of Some Garden Plants in Beijing. Beijing: School of Landscape Architecture, Beijing Forestry University.

Ding, S. F., \& Feng, Z. J. (2019). Evaluation and Analysis of Plant Landscape Quality in the Central Green Belt of Xingang East Road, Guangzhou. Guangdong Landscape Architecture, 41, 73-77.

Gao, Y., \& Hu, J. K. (2017). Construction of Road Plant Landscape Evaluation System in Urban Development Zone Based on AHP Method-Taking Huangpu District of Guangzhou Development Zone as an Example. Inner Mongolia Forestry Science and Technology, 43, 58-61.

He, L. N. (2019). Investigation of Road Greening Status and Analysis of Landscape Characteristics in Weifang City, Green Science and Technology, 70-73.

Li, Z. M. (2016). Research on the Plant Landscape of Urban Roads in Changsha. Changsha: Central South University of Forestry and Technology.

Liao, R. (2019). Research on Urban Road Landscape Evaluation Based on Analytic Hierarchy Process. Hefei: Anhui Agricultural University.

Lin, H., \& Chen, J. H. (2019). Evaluation of the Improvement of Plant Landscape Color in Xiamen Huandao Road Based on Analytic Hierarchy Process, Subtropical Plant Science, 48, 63-69.

Qi, X. (2018). Evaluation and Analysis of Shenyang Urban Road Plant Landscape Based on AHP. Liaoning Agricultural Sciences, 5, 29-34.

Ren, W. L. (2017). Investigation and Analysis of Road Greenbelt Plant Landscape in the New Urban Area of Chifeng City. Hohhot: Inner Mongolia Agricultural University.

Shen, W., Li, K., \& Wang, X. R. (2018). Comprehensive Application of Analytic Hierarchy Process and Beauty Degree Evaluation Method in Plant Landscape Evaluation. 
Northern Horticulture, 11, 110-117.

Xu, S. B. (1988). Practical Decision-Making Method: The Principle of Analytic Hierarchy Process. Tianjin: Tianjin University Press.

Yuan, J. H. (2013). Quantitative Evaluation of Urban Road Plant Landscape in Nanchang Based on AHP Method. Western Forestry, 42, 57-61.

Zou, J. C. (2020). Current Status and Optimal Design of Plant Landscape of Urban Roads in Yangzhou City. Popular Literature and Art, 105-106. 